\title{
Nutritional survey in critically ill children: a single center study in China
}

\author{
Jingjing Li, Biru Li, Juan Qian, Jian Zhang, Hong Ren, Botao Ning, Ying Wang \\ Department of Pediatric Intensive Care Unit, Shanghai Children's Medical Center, Shanghai Jiao Tong University School of Medicine, Shanghai, \\ China \\ Contributions: (I) Conception and design: Y Wang; (II) Administrative support: Y Wang, B Ning; (III) Provision of study materials or patients: J Li, B \\ Li, J Qian, J Zhang, H Ren; (IV) Collection and assembly of data: J Li; (V) Data analysis and interpretation: J Li, B Ning, Y Wang; (VI) Manuscript \\ writing: All authors; (VII) Final approval of manuscript: All authors. \\ Correspondence to: Botao Ning; Ying Wang. Department of Pediatric Intensive Care Unit, Shanghai Children's Medical Center, Shanghai Jiao Tong \\ University School of Medicine, 1678 Dongfang Road, Shanghai, China. Email: ywang_picu@shsmu.edu.cn; ningbotao@scmc.com.cn.
}

Background: The incidence of malnutrition in children, who were admitted to the pediatric intensive care unit (PICU), has kept high level over the past 30 years. In addition, nutrition status of critically ill children deteriorates further during the changing of their conditions and may have a negative effect on patients' outcomes. This study aimed to determine the nutritional status of critically ill children and to survey current nutrition practices and support in PICU.

Methods: In this prospective observational study, 360 critically ill children stayed in the PICU not less than 3 days from Feb. to Nov. in 2017 were enrolled. Each patient underwent nutrition assessment. Nutritional status was determined using Z-scores of length/height-for-age (HAZ), weight-for-age (WAZ), weight-for-height (WHZ), body mass index-for-age (BAZ), based on the World Health Organization child growth standards. We also observed the patients' intake of calories and protein during the first 10 days after admission.

Results: Three hundred and sixty were enrolled in the study. One hundred and eighty-six patients (51.67\%) were malnourished at PICU admission, above 50\% and 56.45\% (105/186) of malnourished patients had severe malnutrition. Except fasting in case of clinical instability in $5.3 \%(19 / 360)$, nutrition was provided in the form of oral feeding in 26.6\% (96/360), enteral nutrition (EN) in 56.1\% (202/360), parenteral nutrition (PN) in 6.4\% (23/360) and mixed support (EN + PN) in 5.6\% (20/360). Totally 384 times interruption of feeding happened in the process of EN, and 1.9 times feeding interruption happened to each patient. Twenty-seven point two percent of these patients had more than three times feeding interruption. The severe malnutrition group had significantly greater length of ICU stay and higher mechanical ventilation support rate $(\mathrm{P}=0.007$, $\mathrm{P}=0.029)$. Total 44 (44/360, 12.22\%) patients died in the study, and the malnutrition was not statistically different between survivor group and death group $(\mathrm{P}=0.379)$. More than $85 \%$ of the patients had lower daily nutritional intake compared with prescribed goals. Sixty-eight point three percent of the patients received the required calories during EN with median time of 2 [2-4] days. Only 32.7\% of patients underwent EN received estimated protein requirements.

Conclusions: These results showed that malnutrition was common among children admitted to PICU. Furthermore, nutrition delivery was generally inadequate in critically ill children, and nutritional status was getting worsening during PICU.

Keywords: Malnutrition; enteral nutrition (EN); nutrition therapy (NT); children; intensive care unit (ICU)

Submitted Dec 25, 2019. Accepted for publication Jun 04, 2020.

doi: $10.21037 / \mathrm{tp}-19-173$

View this article at: http://dx.doi.org/10.21037/tp-19-173 


\section{Introduction}

Malnutrition occurred frequently for children in pediatric intensive care unit (PICU), ranging from $35 \%$ to $72 \%$. Children in PICU suffered high risk of malnutrition due to variable energy requirements and limited energy reservation. Most poor clinical outcomes, including prolonged length of PICU stay, clinical complications, high medical cost and rising mortality, were closely related to malnutrition (1-7). Nutrition assessment patient in PICU is recommended by the American Society for Parenteral and Enteral Nutrition (A.S.P.E.N.) and optimal nutrition therapy (NT) in pediatric critical care in the Asia-Pacific and Middle East: a consensus to identify malnutrition and evaluate whether an energy supply meets the actual requirements $(8,9)$.

Optimal nutrition is important for sever ill children in PICU. However due to digestive intolerance, fluid restrictions and feeding interruption for diagnostic and therapeutic procedures, etc., nutrition treatment is still a challenge in PICU (10). The cumulative effect of suboptimal nutrition delivery may result in significant caloric malnutrition. The aim of our study was to observe the prevalence of malnutrition and feeding patterns in critically ill children. We aimed to determine whether the total daily energy delivery was accordant with the energy and protein guidelines and identify the factors that were associated with suboptimal nutritional intake in the first 10 days of NT.

We present the following article in accordance with the STROBE reporting checklist (available at http://dx.doi. org/10.21037/tp-19-173).

\section{Methods}

\section{Participants}

Participants were eligible for enrollment if they met the following criteria: (I) aged 1 month to 18 years, (II) stayed in PICU longer than 72 hours. Patients who had more than one PICU admission, patients supported by enteral nutrition (EN) and/or parenteral nutrition (PN) in recent 3 months, genetic metabolic disease and HIV infection were excluded. The study was conducted in accordance with the Declaration of Helsinki, and was approved by the Ethics Committee of Shanghai Children's Medical Center (No. SCMCIRB-K2013002) and informed consent was taken from all the patients.
All children admitted to the PICU of Shanghai Children's Medical Center between February 2017 and November 2017 were eligible.

\section{Anthropometric and clinical information}

Anthropometric nutrition assessment was performed among enrolled children at PICU admission and discharge. Nutrition status was determined from the $\mathrm{Z}$-scores of weight-for-height (WHZ), weight-for-age (WAZ), length/ height-for-age (HAZ), body mass index-for-age (BAZ, for children elder than 5 years), based on the World Health Organization child growth standards (11,12). Malnutrition was defined for cases in which rates lower than $-2 \mathrm{Z}$ scores, whereas severe malnutrition was attributed in cases below $-3 \mathrm{Z}$ scores.

Demographic and clinical data were collected on age, sex, height, admission weight, admission diagnosis, pediatric risk of mortality score (PRISM III) (13), mechanical ventilation time, PICU stay, hospital stay, hospitalization expense, and clinical outcomes. In order to calculate the total daily energy intake (EI), the data of enteral and or PN delivery were collected. The end point for nutrition delivery data was 10 days after admission or the day of discharge from the PICU.

\section{Energy expenditure and protein requirements}

Predicted energy expenditure (PEE) was calculated for each subject as $125 \%$ of the predicted basal metabolic rate according to the Schofield-HTWT equation (14) (see Table 1). Energy adequacy was calculated using EI to PEE ratio: underfeeding was defined as $<90 \%$, adequate feeding as $90-110 \%$, and overfeeding as $>110 \%$ (15). Estimated protein requirements were determined according to A.S.P.E.N. guidelines for critically ill children ( $<2 \mathrm{yrs}, 2-3 \mathrm{~g} / \mathrm{kg} ; 2-$ $13 \mathrm{yrs}, 1.5-2 \mathrm{~g} / \mathrm{kg} ; \geq 13 \mathrm{yrs}, 1.5 \mathrm{~g} / \mathrm{kg}$ ) (8).

\section{Statistical analyses}

Statistical analyses were carried out with SPSS software (version 17.0). $t$-test and analysis of variance were used for normal distribution and continuous variables. Wilcoxon signed rank test or Kruskal-Wallis test was performed for non-normally distribution. $\chi^{2}$ test or Fisher's exact test was carried out for categorical variables. Tests of significance were two-sided, and statistical difference was considered significantly if $\mathrm{P}<0.05$. 
Table 1 Schofield-HTWT equation (kcal/day) (14)

\begin{tabular}{lcc}
\hline Age & Sex & Schofield-HTWT equation \\
\hline 0-3 years & Male & $0.167 \mathrm{~W}+15.174 \mathrm{H}-617.6$ \\
& Female & $16.252 \mathrm{~W}+10.232 \mathrm{H}-413.5$ \\
3-10 years & Male & $19.59 \mathrm{~W}+1.303 \mathrm{H}+414.9$ \\
& Female & $16.969 \mathrm{~W}+1.618 \mathrm{H}+371.2$ \\
10-18 years & Male & $16.25 \mathrm{~W}+1.372 \mathrm{H}+515.5$ \\
& Female & $8.365 \mathrm{~W}+4.65 \mathrm{H}+200.0$ \\
\hline
\end{tabular}

$\mathrm{H}$, height (cm); W, weight $(\mathrm{kg})$.

\section{Results}

The characteristics of total patients were summarized in Table 2. During the study period, the 920 patients admitted to the PICU, 360 were enrolled in the study. One hundred and eighty-six patients $(51.67 \%)$ were malnourished at PICU admission, and $56.45 \%$ (105/186) of malnourished patients had severe malnutrition. Except fasting in case of clinical instability in $5.3 \%(19 / 360)$, nutrition was provided in the form of oral feeding in $26.6 \%(96 / 360), \mathrm{EN}$ in $56.1 \%$ (202/360), PN in 6.4\% (23/360) and mixed support (EN $+\mathrm{PN})$ in $5.6 \%$ (20/360). Among the $202 \mathrm{EN}$ patients, 200 children was delivered via the gastric tube (200/202), and only 2 of them was via post-pyloric route. $\mathrm{EN}$ was started 3.5 [2-14] hr after PICU admission (Table 2). In the 10 days of $\mathrm{EN}, 69.3 \%$ of the patients underwent some issues, such as prescribed energy expenditure, airway management and radiology, which interrupted enteral feeding frequently. Totally 384 times interruption of feeding happened in the process of $\mathrm{EN}$, and 1.9 times feeding interruption happened to each patient. Twenty-seven point two percent of these patients had more than three times feeding interruption, barriers to deliver calories include: (I) invasive manipulation or surgery in $28.1 \%$ (108/384): endotracheal intubation, extubation, fiber colonoscopy, etc.; (II) imaging examination in $48.7 \%$ (187/384): ultrasound, CT, MRI, etc.; (III) feeding intolerance in $15.6 \%$ (60/384): gastric retention, abdominal distention, diarrhea, etc.; (IV) others in 7.6\% (29/384): clinical instability, fluid restriction, etc. (Table 2).

The patients had significantly lower mean $( \pm \mathrm{SD}) \mathrm{HAZ}$ $(-1.75 \pm 1.95)$, WAZ $(-1.74 \pm 1.86)$, and BAZ $(-0.88 \pm 2.04)$ at PICU discharge, as compared to the mean HAZ $(-1.52 \pm 1.93)$, WAZ $(-1.50 \pm 1.87)$, and BAZ $(-0.56 \pm 1.90)$ at PICU admission (Table 3). However, no differences were detected in the prevalence of malnutrition $\left(\chi^{2}=2.949\right.$,
Table 2 Demographic and clinical characteristics of critically ill children $(\mathrm{n}=360)$

\begin{tabular}{|c|c|}
\hline Characteristics & Value \\
\hline Sex (male/female) & $214 / 146$ \\
\hline Age, M (IQR), month & $9(3-40.5)$ \\
\hline PRISM III, M (IQR) & $7(3.25-11)$ \\
\hline Mortality, n (\%) & $44(12.2)$ \\
\hline \multicolumn{2}{|l|}{ Nutritional status at admission, $\mathrm{n}(\%)$} \\
\hline Malnutrition & $181(51.67)$ \\
\hline Severe malnutrition & $105(56.45)$ \\
\hline \multicolumn{2}{|l|}{ Nutritional status at discharge, $\mathrm{n}(\%)$} \\
\hline Malnutrition & $202(56.1)$ \\
\hline Severe malnutrition & $121(59.9)$ \\
\hline \multicolumn{2}{|l|}{ Admission diagnosis, $\mathrm{n}(\%)$} \\
\hline Respiratory & $159(44.2)$ \\
\hline Sepsis/septic shock & $45(12.5)$ \\
\hline Neurologic & $22(6.1)$ \\
\hline Cardiovascular & $33(9.2)$ \\
\hline Post-operation & $46(12.8)$ \\
\hline Others & $55(15.3)$ \\
\hline \multicolumn{2}{|l|}{ Feeding methods, $\mathrm{n}(\%)$} \\
\hline Oral feeding & $96(26.6)$ \\
\hline EN & $202(56.1)$ \\
\hline PN & $23(6.4)$ \\
\hline Mixed support (EN + PN) & $20(5.6)$ \\
\hline Fasting lasting over $72 \mathrm{hr}$ & $19(5.3)$ \\
\hline Feeding interruption, $\mathrm{n}(\%)$, times & 384 \\
\hline Invasive manipulation or surgery & $108(28.1)$ \\
\hline Imaging examination & $187(48.7)$ \\
\hline Feeding intolerance & $60(15.6)$ \\
\hline Others & $29(7.6)$ \\
\hline Mechanical ventilation, $\mathrm{n}(\%)$ & $138(38.3)$ \\
\hline Length of mechanical ventilation, $M[I Q R], d$ & $10.25[5-17]$ \\
\hline Nososcomial infection, $\mathrm{n}(\%)$ & $30(8.3)$ \\
\hline Length of PICU stay, M [IQR], d & $9[6-15]$ \\
\hline Length of hospital stay, M [IQR], d & 19 [11-30] \\
\hline Hospitalization expense, $M(\mathrm{IQR}), \times 10^{3}$ yuan & $37.6(17.2-83.5)$ \\
\hline
\end{tabular}


Table 3 Comparison of $Z$ scores between admission and discharge

\begin{tabular}{lcccr}
\hline Z score & Cases & At admission & At discharge & $\mathrm{t}$ \\
\hline WAZ & 289 & $-1.50 \pm 1.87$ & $-1.74 \pm 1.86$ & 8.479 \\
HAZ & 289 & $-1.52 \pm 1.93$ & $-1.75 \pm 1.95$ & 0.000 \\
WHZ & 289 & $-0.48 \pm 1.86$ & $-0.54 \pm 1.91$ & 6.913 \\
BAZ & 71 & $-0.56 \pm 1.90$ & $-0.88 \pm 2.04$ & 1.650 \\
\hline
\end{tabular}

HAZ, WAZ and WHZ used for patients under 5 years old; BAZ used for patients older than 5 years old. WAZ, weight-for-age Z score; HAZ, length/height-for-age $Z$ score; WHZ, weight-for-height $Z$ score; BAZ, body mass index-for-age $Z$ score.

Table 4 Comparison of clinical outcomes between different nutrition status at admission

\begin{tabular}{|c|c|c|c|c|c|}
\hline Variables & $\begin{array}{c}\text { Normal nutrition } \\
\text { group }\end{array}$ & $\begin{array}{l}\text { Mild to moderate } \\
\text { malnutrition group }\end{array}$ & $\begin{array}{l}\text { Severe malnutrition } \\
\text { group }\end{array}$ & Value & $\mathrm{P}$ \\
\hline Cases & 174 & 81 & 105 & & \\
\hline Age, M [IQR], month & $19.5[5-65.25]$ & $6[2-18]^{a}$ & $5[2-13]^{a}$ & $\mathrm{H}=34.155$ & 0.000 \\
\hline Length of mechanical ventilation, M [IQR], $d$ & 8 [4-14.625] & $15[5-20]$ & $11[7-17]$ & $\mathrm{H}=3.239$ & 0.198 \\
\hline Number of organ dysfunction, M [IQR] & $1[0-2]$ & $1[0-2]$ & $1[1-2]$ & $\mathrm{H}=5.610$ & 0.060 \\
\hline \multicolumn{6}{|l|}{ Comorbidities, n (\%) } \\
\hline Length of hospital stay, M (IQR), d & $16.5(10-29.25)$ & $20(10-29.5)$ & $21(12.5-30.5)$ & $\mathrm{H}=2.409$ & 0.300 \\
\hline Hospitalization expense, $M(I Q R), \times 10^{4}$ yuan & $3.35(1.63-8.00)$ & $3.33(1.49-7.19)$ & $4.36(1.90-8.88)$ & $\mathrm{H}=3.713$ & 0.156 \\
\hline Mortality follow-up 28 days out of PICU, n (\%) & $24(13.8)$ & $7(8.6)$ & $13(12.4)$ & $\chi^{2}=1.370$ & 0.504 \\
\hline
\end{tabular}

Non-normal distribution measurement data analyzed by Kruskal-Wallis test; compared with the normal nutrition group, ${ }^{a}, \mathrm{P}<0.05$; compared with the mild to moderate nutrition group, ${ }^{b}, \mathrm{P}<0.05 . \mathrm{M}(\mathrm{IQR})$, median (interquartile range); MODS, multiple organ dysfunction syndrome; PICU, pediatric intensive care unit.

$\mathrm{P}=0.086)$ or severe malnutrition $\left(\chi^{2}=0.634, \mathrm{P}=0.426\right)$ between admission and discharge.

Patients with mild/moderate malnutrition and severe malnutrition at admission were younger than those without malnutrition $\{6[2-18]$ and $5[2-13]$ vs. 19.5 (5-65.25) months, $\mathrm{P}=0.000\}$; Severe malnutrition group also had significantly greater length of ICU stay [11 (6-19.5) vs. 8 (5.38-13) days, $\mathrm{P}=0.007]$. Mechanical ventilation support rate of severe malnutrition group was higher than normal nutrition and mild/moderate groups $(48.6 \%$ vs. $35.6 \%$ and $30.9 \%, \mathrm{P}=0.029)$. The clinical outcomes between different nutrition status at admission were analyzed in Table 4.

Nutritional status showed a worsening trend during PICU stays, 202 children (56.1\%) were malnourished at discharge, $59.9 \%(121 / 202)$ of them were severe malnutritional, among them 31 patients were normal nutrition status when they admit to PICU. The risk factors for worsen nutrition status during hospitalization in PICU were analyzed in Table 5, but there were no significant risk factors found, such as nososcomial infection, time to start $\mathrm{EN}$, average energy and protein intake, calorie and protein compliance rate and number of feeding interruptions, etc. 
Table 5 Analysis of risk factors for worsen nutrition status during hospitalization in PICU

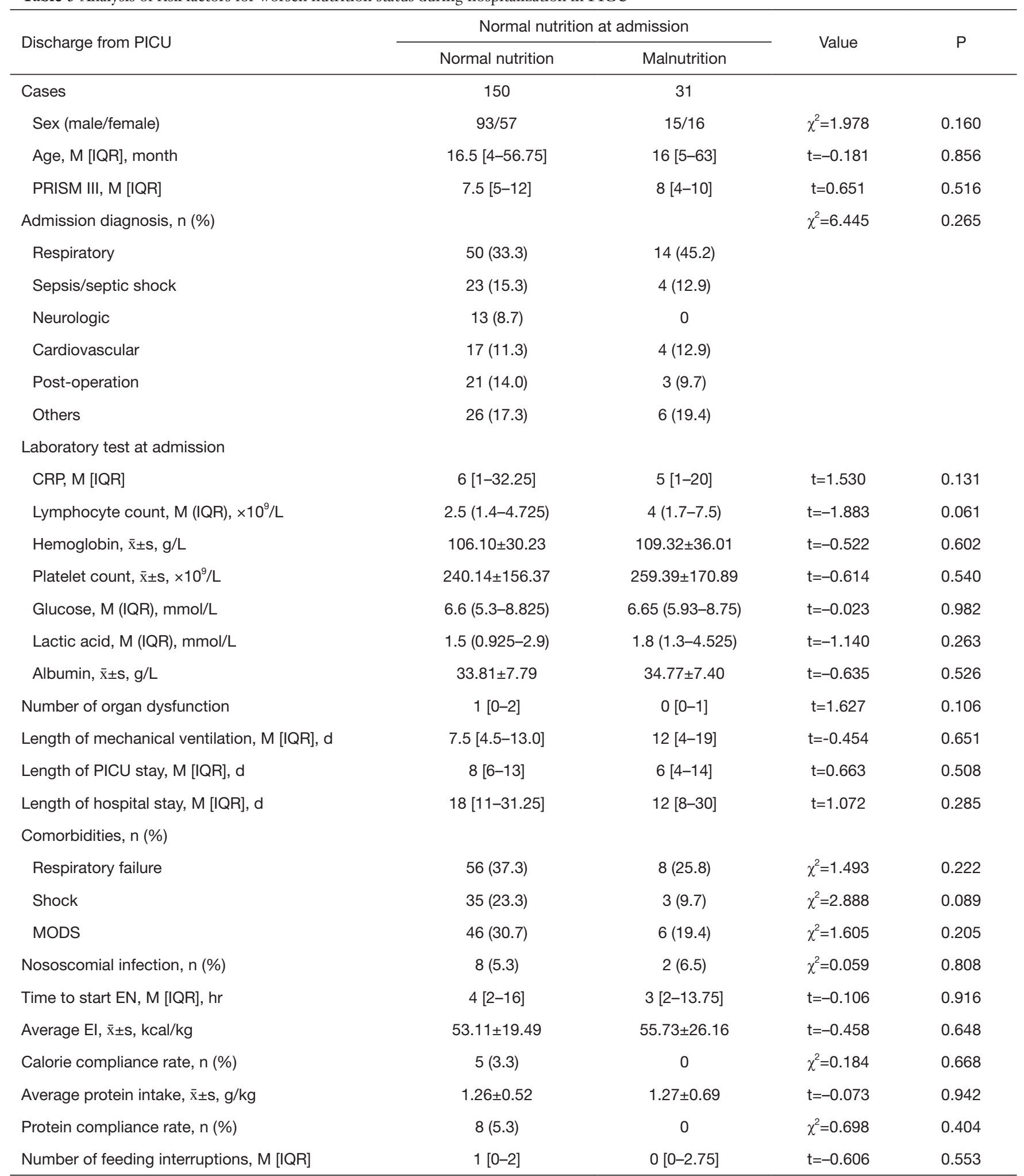

PICU, pediatric intensive care unit; M (IQR), median (interquartile range); PRISM III, pediatric risk of mortality III; CRP, C-reactive protein; MODS, multiple organ dysfunction syndrome; EN, enteral nutrition; El, energy intake. 
Table 6 Analysis of univariate variables related to death in critically ill children

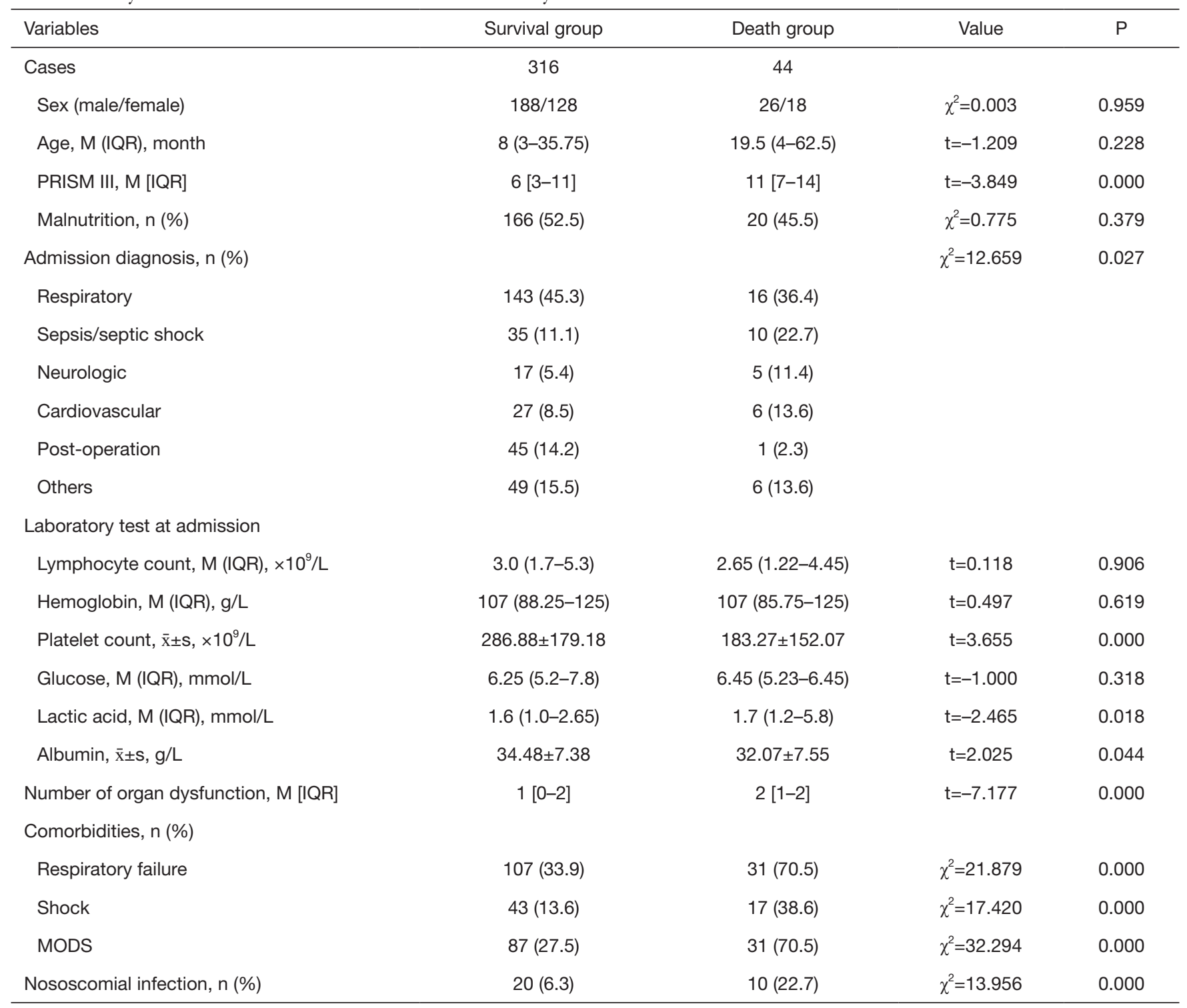

M (IQR), median (interquartile range); PRISM III, pediatric risk of mortality III; MODS, multiple organ dysfunction syndrome.

Total 44 (44/360, 12.22\%) patients died in the study, after carried out the analysis of univariate variables related to death in critically ill children (Table 6), the malnutrition was not statistically different between survivor group and death group $(\mathrm{P}=0.379)$. The following factors such as PRISM III, platelet count, number of organ dysfunction, comorbidities, nososcomial infection, plasma albumin level and plasma lactic acid level, were associated with the death group.

Sixty-eight point three percent of the patients received the required calories during $\mathrm{EN}$ with median time of 2
[2-4] days. The PEE calculated according to the SchofieldHTWT equation was 349.3 (243.3-581.1) kcal/day. Comparison of PEE with the total EI showed that underfeeding occurred on 799 days $(48.5 \%)$, adequate feeding on 327 days (31.7\%), and overfeeding on 523 days (19.8\%).

In the former 10 days in PICU after admission only $32.7 \%$ of patients underwent EN received estimated protein requirements, but the actual protein intake was significantly lower than A.S.P.E.N. guidelines $(\mathrm{P}<0.001)$ (Figure 1). 


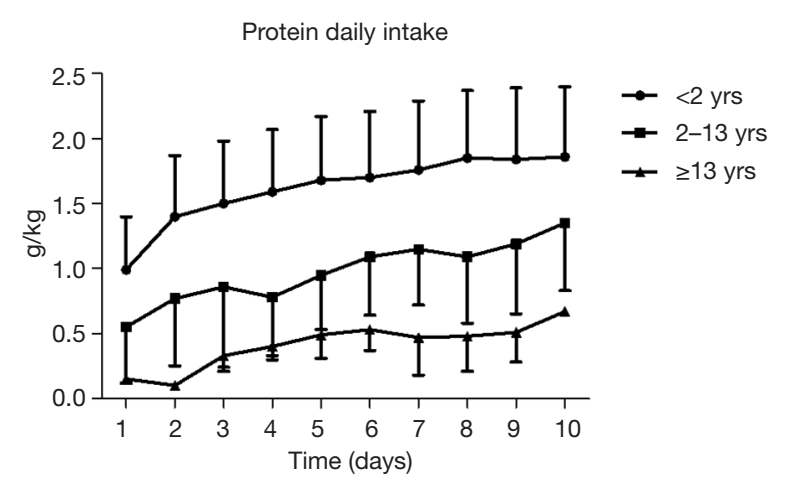

Figure 1 Protein intake in PICU patients. PICU, pediatric intensive care unit.

\section{Discussion}

Malnutrition is common in PICU, and this factor is related to adverse consequences $(9,16,17)$. Leite et al. (4) observed $47.1 \%$ of the patients were malnourished on admission to the ICU, and the mortality odds ratio $(\mathrm{OR}=3.98)$ was higher in malnourished patients with hyperglycemia $(\mathrm{P}=0.03)$ after adjusting for clinical severity; hypoglycemia was related with longer ICU stay and fewer ventilator-free days $(\mathrm{OR}=6.5$ and $\mathrm{OR}=4.11$, respectively; both $\mathrm{P}<0.01)$. In a prospective cohort study, malnutrition was found to be a risk factor for length of ICU stay and also related with length of ventilation more than 5 days $(\mathrm{OR}=1.76 ; \mathrm{P}=0.024)$ (7). Castillo et al. (7) studied critically ill children receiving continuous renal replacement therapy (CRRT) and found mortality for patients with weight less than the third percentile (P3) was greater than that with weight more than P3 (51\% vs. 33\%; P=0.037). In addition, the only factor associated with mortality was malnutrition in the univariate and multivariate logistic regression analyses $(\mathrm{OR}=2.11$; 95\% CI, 1.067-4.173; P=0.032). In our study, $51.67 \%$ of children were acutely and/or chronically malnourished upon admission to PICU, above $50 \%$ of those malnourished children had severe malnutrition. We also found children with malnutrition had greater length of PICU stay $(\mathrm{P}=0.001)$ and mechanical ventilation support rate $(\mathrm{P}=0.029)$.

Some study showed that reasonable nutrition treatment was related with better outcomes in the treatment of malnourished ICU patients (18-20). Therefore, the administering of optimal NT is an essential measure of critical care, which aims to provide patients adequate calories for curing malnutrition or preventing progression of malnutrition (21-23). It is well known EN is the preferred mode of nutrient administering for severe illness children with a functioning gastrointestinal tract, if tolerated (9). Although we have attached importance to NT in critically ill children, the protein and energy deficits were often observed during PICU stay, common factors contributing to that deficits include: (I) increased demands secondary to the metabolic stress response, (II) inadequate substrate delivery at the bedside, and (III) failure to estimate energy expenditure accurately (24). In a study of NT of 90 consecutive patients in a tertiary pediatric ICU in Brazil, Zamberlan et al. (25) found NT was initiated within 72 hours after admission averagely; Among them, 80\% children received $\mathrm{EN}$ therapy, only $10 \%$ received $\mathrm{PN}$, and the rest underwent mixed NT $(\mathrm{EN}+\mathrm{PN})$. Although most patients were abrosia from hospital admission, they received adequate nutrition delivery at the end of the first week, with an average EI of $82 \mathrm{kcal} / \mathrm{kg} / \mathrm{d}$ and protein intake of $2.7 \mathrm{~g} / \mathrm{kg} / \mathrm{d}$. They still found arm circumference and triceps skinfold thickness significantly decreased $(\mathrm{P}<0.001)$. In a retrospective evaluation of 240 PICU patients, the actual EI for during hospitalization was significantly lower than basal metabolic rate $(75.7 \% \pm 56.7 \%, \mathrm{P}<0.001)$, and the actual protein intake came to an average of $40.4 \% \pm 44.2 \%$ of protein requirements, which was significantly lower than the ASPEN guidelines $(\mathrm{P}<0.001)(26)$. Keehn et al. (27) evaluated NT in 100 critically ill children, found the mean of nutrition initiation time was 22.8 (16.6) hours, NT was interrupted 1.2 (2.0) times per patient; interruption duration caused by surgery and planned extubation was significantly longer than all other interruption $(\mathrm{P}<0.001$ and $\mathrm{P}=0.001$, respectively). We recorded NT administered to 360 critically ill children admitted to PICU for longer than 72 hours, and found $68.1 \%$ of the patients received EN or/and PN. Nutrition status during hospitalization of PICU showed a worsening trend, there were statistically significant differences in WAZ, HAZ and BAZ in our study. We believed that nutrition depletion was associated with deficiencies of the daily calories and protein intake. In the first 10 days of $\mathrm{EN}$, there was 1.9 times feeding interruption per person. Invasive operation and imaging examination were the main barriers to deliver prescribed calories. On the one hand, prescription calories and protein have to be reduced because of clinical instability, feeding intolerance or fluid volume restriction; on the other hand, the prescribed energy was failed to deliver due to feeding interruption caused by imaging examination, intubation, extubation, etc. Optimal and effective implementation of NT in critically ill children is still a tough issue. Although there were 31 patients transited to malnutrition from 
normal nutrition at discharge, but no significant factors were found to be associated with it, including feeding interruption, time to start $\mathrm{EN}$, average energy and protein intake, calorie and protein compliance rate and number of feeding interruptions, etc. Maybe the reason was that this was a small size sample and single center study.

The evaluation and selection of nutrition support should be an essential component for all hospitalized children. The primary indication for starting nutrition support is aimed to prevent or treat malnutrition patients who were disable to maintain adequate intake orally. Energy expenditure varies during critical illness, reasonable caloric supply has become an important component of NT. Feeding status could be determined by the respiratory quotient (RQ), or EI to energy requirements ratio. Using a measured RQ less than 0.85 to recognize underfeeding, which had high specificity $(87 \%)$ but low sensitivity $(27 \%)$; a measured RQ more than 1.0 had low sensitivity (21\%) and high specificity (98\%) for identifying overfeeding (28). de Oliveira Iglesias et al. (15) evaluated that the ratio of delivered energy versus required energy was $90 \%$ in $55.7 \%$ of the $\mathrm{EN}$ days, and revealed that low prescription was the main reason for not achieving the energy goal during the first 5 days' EN. Mehta et al. (29) observed that the energy expenditure was often overestimated through standard equations, and a high incidence of overfeeding reached to $83 \%$ with cumulative energy excess of up to $8,000 \mathrm{kcal} /$ week was found, especially in children less than 1 year. Indirect calorimetry had not been used and energy requirements were calculated with the Schofield-HTWT equation in the study. Comparison of PEE with the total EI showed that $48.5 \%$ of those nutrition days were underfeeding, $19.8 \%$ overfeeding, and only $31.7 \%$ adequate feeding in the $1,649 \mathrm{EN}$ days. Cumulative negative energy balances exacerbated malnutrition, which was correlated with greater length of PICU stay.

This study has some limitation. Firstly, predictive formula instead of indirect calorimetry was used during energy expenditure calculating. Secondly, this study was performed in a single center, and the ages, weights, diagnoses of the enrolled patients were different in wide range.

In conclusion, malnutrition is common among children admitted to PICU. Although the Schofield-HTWT equation would provide estimated individual energy requirements and may guide nutrition prescription, NT may be intolerable among most of critically ill children due to disease progression or treatments, such as stress ulceration, intestinal paralysis, internal environment disorders, liquid limitation and invasive operation. Further research to improve individual NT in critically ill children would be in progress.

\section{Acknowledgments}

Funding: The Project was Support by the Shanghai Natural Science Foundation of China (No. 19ZR1432900).

\section{Footnote}

Reporting Checklist: The authors have completed the STROBE reporting checklist. Available at http://dx.doi. org/10.21037/tp-19-173

Data Sharing Statement: Available at http://dx.doi. org/10.21037/tp-19-173

Peer Review File: Available at http://dx.doi.org/10.21037/tp19-173

Conflicts of Interest: All authors have completed the ICMJE uniform disclosure form (available at http://dx.doi. org/10.21037/tp-19-173). The authors have no conflicts of interest to declare.

Ethical Statement: The authors are accountable for all aspects of the work in ensuring that questions related to the accuracy or integrity of any part of the work are appropriately investigated and resolved. The study was conducted in accordance with the Declaration of Helsinki, and was approved by the Ethics Committee of Shanghai Children's Medical Center (No. SCMCIRB-K2013002) and informed consent was taken from all the patients.

Open Access Statement: This is an Open Access article distributed in accordance with the Creative Commons Attribution-NonCommercial-NoDerivs 4.0 International License (CC BY-NC-ND 4.0), which permits the noncommercial replication and distribution of the article with the strict proviso that no changes or edits are made and the original work is properly cited (including links to both the formal publication through the relevant DOI and the license). See: https://creativecommons.org/licenses/by-nc-nd/4.0/.

\section{References}

1. Delgado AF, Okay TS, Leone C, et al. Hospital 
malnutrition and inflammatory response in critically ill children and adolescents admitted to a tertiary intensive care unit. Clinics (Sao Paulo) 2008;63:357-62.

2. Bagri NK, Jose B, Shah SK, et al. Impact of malnutrition on the outcome of critically ill children. Indian J Pediatr 2015;82:601-5.

3. Briassoulis G, Briassouli E, Tavladaki T, et al. Unpredictable combination of metabolic and feeding patterns in malnourished critically ill children: the malnutrition-energy assessment question. Intensive Care Med 2014;40:120-2.

4. Leite HP, de Lima LF, de Oliveira Iglesias SB, et al. Malnutrition may worsen the prognosis of critically ill children with hyperglycemia and hypoglycemia. JPEN J Parenter Enteral Nutr 2013;37:335-41.

5. de Souza Menezes F, Leite HP, Koch Nogueira PC. Malnutrition as an independent predictor of clinical outcome in critically ill children. Nutrition 2012;28:267-70.

6. Botrán M, López-Herce J, Mencía S, et al. Relationship between energy expenditure, nutritional status and clinical severity before starting enteral nutrition in critically ill children. Br J Nutr 2011;105:731-7.

7. Castillo A, Santiago MJ, López-Herce J, et al. Nutritional status and clinical outcome of children on continuous renal replacement therapy: a prospective observational study. BMC Nephrol 2012;13:125.

8. Mehta NM, Compher C, A.S.P.E.N. Board of Directors. A.S.P.E.N. Clinical Guidelines: nutrition support of the critically ill child. JPEN J Parenter Enteral Nutr 2009;33:260-76.

9. Lee JH, Rogers E, Chor YK, et al. Optimal nutrition therapy in paediatric critical care in the Asia-Pacific and Middle East: a consensus. Asia Pac J Clin Nutr 2016;25:676-96.

10. Lambe C, Hubert P, Jouvet $P$, et al. A nutritional support team in the pediatric intensive care unit: changes and factors impeding appropriate nutrition. Clin Nutr 2007;26:355-63.

11. de Onis M, Onyango AW, Borghi E, et al. Development of a WHO growth reference for school-aged children and adolescents. Bull World Health Organ 2007;85:660-7.

12. Van den Broeck J, Willie D, Younger N. The World Health Organization child growth standards: expected implications for clinical and epidemiological research. Eur J Pediatr 2009;168:247-51.

13. Pollack MM, Patel KM, Ruttimann UE. PRISM III: an updated Pediatric Risk of Mortality score. Crit Care Med 1996;24:743-52.
14. Schofield WN. Predicting basal metabolic rate, new standards and review of previous work. Hum Nutr Clin Nutr 1985;39 Suppl 1:5-41.

15. de Oliveira Iglesias SB, Leite HP, Santana e Meneses JF, et al. Enteral nutrition in critically ill children: are prescription and delivery according to their energy requirements? Nutr Clin Pract 2007;22:233-9.

16. Skillman HE, Wischmeyer PE. Nutrition therapy in critically ill infants and children. JPEN J Parenter Enteral Nutr 2008;32:520-34.

17. Mehta NM, Skillman HE, Irving SY, et al. Guidelines for the provision and assessment of nutrition support therapy in the pediatric critically ill patient: Society of Critical Care Medicine and American Society for Parenteral and Enteral Nutrition. Pediatr Crit Care Med 2017;18:675-715.

18. Gurgueira GL, Leite HP, Taddei JA, et al. Outcomes in a pediatric intensive care unit before and after the implementation of a nutrition support team. JPEN J Parenter Enteral Nutr 2005;29:176-85.

19. Alberda C, Gramlich L, Jones N, et al. The relationship between nutritional intake and clinical outcomes in critically ill patients: results of an international multicenter observational study. Intensive Care Med 2009;35:1728-37.

20. Wischmeyer PE. Tailoring nutrition therapy to illness and recovery. Crit Care 2017;21:316.

21. Wong JJ, Ong C, Han WM, et al. Protocol-driven enteral nutrition in critically ill children: a systematic review. JPEN J Parenter Enteral Nutr 2014;38:29-39.

22. Mehta NM, Bechard LJ, Cahill N, et al. Nutritional practices and their relationship to clinical outcomes in critically ill children--an international multicenter cohort study*. Crit Care Med 2012;40:2204-11.

23. Sasbón JS. How important is nutritional support in the treatment of the critically ill child?* Crit Care Med 2012;40:2263-4.

24. Mehta NM, Duggan CP. Nutritional deficiencies during critical illness. Pediatr Clin North Am 2009;56:1143-60.

25. Zamberlan P, Delgado AF, Leone C, et al. Nutrition therapy in a pediatric intensive care unit: indications, monitoring, and complications. JPEN J Parenter Enteral Nutr 2011;35:523-9.

26. Kyle UG, Jaimon N, Coss-Bu JA. Nutrition support in critically ill children: underdelivery of energy and protein compared with current recommendations. J Acad Nutr Diet 2012;112:1987-92.

27. Keehn A, O'Brien C, Mazurak V, et al. Epidemiology of interruptions to nutrition support in critically ill children in the pediatric intensive care unit. JPEN J Parenter 
Enteral Nutr 2015;39:211-7.

28. Dokken M, Rustøen T, Stubhaug A. Indirect calorimetry reveals that better monitoring of nutrition therapy in pediatric intensive care is needed. JPEN J Parenter Enteral
Nutr 2015;39:344-52.

29. Mehta NM, Bechard LJ, Dolan M, et al. Energy imbalance and the risk of overfeeding in critically ill children. Pediatr Crit Care Med 2011;12:398-405.

Cite this article as: Li J, Li B, Qian J, Zhang J, Ren H, Ning B, Wang Y. Nutritional survey in critically ill children: a single center study in China. Transl Pediatr 2020;9(3):221-230. doi: 10.21037/tp-19-173 